\title{
Identifying Crowding Impact on Departure Time Choice of Commuters in Urban Rail Transit
}

\author{
Yan Cheng $\mathbb{D}^{1}{ }^{1}$ Xiafei Ye, ${ }^{2,3}$ and Taku Fujiyama ${ }^{1}$ \\ ${ }^{1}$ Centre for Transport Studies, University College London, London WC1E 6BT, UK \\ ${ }^{2}$ MOE Key Laboratory of Road and Traffic Engineering, Tongji University, Shanghai 201804, China \\ ${ }^{3}$ Shanghai Key Laboratory of Rail Infrastructure Durability and System Safety, Tongji University, Shanghai 201804, China
}

Correspondence should be addressed to Yan Cheng; yan.cheng@ucl.ac.uk

Received 15 April 2020; Accepted 23 May 2020; Published 23 June 2020

Academic Editor: Andrea D’Ariano

Copyright ( 92020 Yan Cheng et al. This is an open access article distributed under the Creative Commons Attribution License, which permits unrestricted use, distribution, and reproduction in any medium, provided the original work is properly cited.

Crowding in urban rail transit is an inevitable issue for most of the high-density cities across the world, especially during peak time. For commuters who have considerably fixed destination arrival times, departure time choice is an important tool to adjust their trips. The ignorance of crowding impact on commuters' departure time choice in urban rail transit may cause errors in forecasting dynamic passenger flow during peak time in urban rail transit. The paper develops a mixed logit model to identify how crowding impacts the departure time choice of commuters and their taste variation. Arrival time value was firstly measured in a submodel by applying the reference point approach and then integrated to the main model. Considering the characteristics of human perception, we divided crowding into five grades with distinct circumstances. All parameter distributions were assumed based on their empirical distributions revealed through resampling. The data from Shanghai Metro used for estimation were collected by a specifically designed survey, which combines revealed preference questions and stated preference experiments to investigate the willingness and extent of changing departure time choice of passengers who experienced various grades and duration of crowding in the most crowded part. The result shows that an asymmetric valuation model with preferred arrival time as the only reference point best captured commuters' responses to arrival time. The departure time choice model clearly identified that only crowding ranging from Grades 3 to 5 had an impact on commuters' departure time choice. The parameters of crowding costs can be assumed to follow transformed lognormal distributions. It is found that the higher the grade of crowding is, the bigger the impact each unit of crowding cost has on commuters' departure time choice, while commuters' tastes get more concentrated when crowded situation upgrades. The model in this paper can help policymakers better understand the interaction between commuters' departure time choice and crowding alleviation.

\section{Introduction}

Crowding in urban rail transit is an inevitable issue for most of the high-density cities in the world, especially during peak time. Crowding itself is an aggregate result of passengers' departure time choice and route choice, both of which are fundamental behaviours considered in dynamic passenger assignment models in urban rail transit. But meanwhile, crowding can also affect both choices, which leads to a new network status. Passengers may react to crowding by adapting their travel behaviours, such as departing earlier or later to avoid crowding, using a different line.
A number of studies have paid attention to the influence of crowding on passenger assignment in urban rail transit, especially on route choice [1-6]. It was proved not only crowding delay but also crowding itself were equilibrated in the route choice of metro passengers [2]. Except crowding delay, crowding may cause physical inconvenience (e.g., seat unavailability and squeezing with people), extra psychological pressure (e.g., less privacy and higher risk of personal safety and security), and long-term ill health [7-9]. Although the fact that crowding matters to passengers has been pointed out by the existing literature, the questions how passengers perceive crowding in their subjective way, whether all degrees of crowding have an identical influence 
on passengers' behavioural changes, and if not, what the differences are still need more research.

Apart from changing route choice, another practical response of passengers to crowding is changing departure time. The survey carried out by Maunsell [10] reported that $25-28 \%$ of the respondents stated that they set off earlier or later than preferred in order to travel in less crowded conditions. For commuters who have considerably fixed destination arrival times, they would try to update their departure times based on their own experience instead of keeping the same all the time. However, the impact of crowding on the departure time choice of commuters in urban rail transit has been scarcely studied. The ignorance of crowding impact on departure time choice of commuters may cause errors in predicting dynamic passenger flow during peak time in urban rail transit. This paper aims at constructing a departure time choice model that identifies how crowding impacts the departure time choice of commuters in urban rail transit. It will be integrated in a potential dynamic transit assignment model by combining with route choice and update models to predict within-day and day-to-day passenger patterns in the future.

Departure time choice was first studied in road traffic since 1980s. Schedule models, reliability-based models, and activityschedule based models were developed in both econometric modelling [11-17] and dynamic user equilibrium analysis fields [18-24]. Despite the different methods used in these models, the main concerns keep the same as exploring the relation between travel time uncertainties caused by congestion and arrival time value which is usually interpreted as schedule delay. Congestion is a major response of road network with insufficient supply to excess travel demand. Travellers departing at different times in the road network may experience various levels of congestion, which directly leads to the changes in arrival time at destination. However, urban rail transit has significant differences with road traffic in terms of network structure, operation scheme, and demand characteristics. In an exclusive right-of-way urban rail transit network, the response to insufficient supply is no longer congestion; instead, it is crowding. An increase of passengers has no influence on the speed, so in-vehicle travel time between stations remains unchanged. Alternatively, the growing number of passengers leads to an aggravation of in-vehicle crowding, an extension of boarding and alighting time, and an extra waiting time for the passengers who cannot board the first incoming train. Passengers choose their departure time by mainly considering the trade-off between arrival time value and crowding. The viewpoint was agreed by most of the research studies on departure time choice in urban rail transit [25-31] in the past two decades. However, both components and the relation between them are worthy of further studies.

Arrival time value is mostly converted to schedule delay [32] for measuring the disutility of arriving at destination earlier or later than preferred in existing research studies. The desired arrival time is predetermined as official work/school start time [27-31, 33-35]. Although recently researchers tried to relax this assumption $[25,26,36]$, very few studies investigated how this time point should be fixed. In addition, the schedule delay is assumed to be a linear function [27, 29-31, 34], which ignores the different responses of commuters to every unit increase of the difference between actual and desired arrival time, on either early-arrival or late-arrival side. Nonlinear functions $[33,37]$ are used to relax this assumption for accommodating the different responses. But the functions are convex with fixed parameters, which assumes passengers are risk-seeking when they arrive later than work/school start time.

Crowding valuation is the other research point. It is mainly quantified by monetary equivalent, i.e., willingness-to-pay [38-40] and extra travel time [8, 41-44] with both revealed preference (RP) and/or stated preference (SP) data. The latter is found to be more transferrable across different contexts, including countries [8]. In this method, crowding cost is calculated by multiplying the degree of crowding with in-vehicle time, that is, the degree of crowding is quantified as a time multiplier to describe passengers' perceptions of crowding, which can be seen as the crowding cost per unit of in-vehicle time.

In both quantification methods of crowding, the key issue is how to measure the degree of crowding. Objective metrics are widely used by transport authorities in different countries, such as the passengers in excess of capacity (PiXC) [45], the number of standing passengers per square meter [46], load factor, and the level of service (LOS) [47]. Meanwhile, crowding is traditionally assumed to be monotonically an increasing function of in-vehicle passenger density by researchers [30, 48], normally a linear function. While these objective density-based metrics are used to measure crowding, passengers perceive crowding in a more subjective way according to surveys [49]. Their perceptions of crowding are affected by situational, emotional, and behavioural factors. Empirical studies also indicated that passenger density may not be simply and linearly related to the perception of crowding $[7,8,39]$, that's why more researches discretised the degrees of crowding in a finite set of grades. These grades are measured by passengers through purely stated preference survey with various criteria, such as occupancy rate or number of passengers per square meter $[5,8,37,42,44]$ or their crowding status, e.g., sitting or standing [41, 50, 51]. However, based on the stated preference survey, the degrees of crowding are fixed in different scenarios. The limited alternatives may distort the passengers' perceptions of crowding.

Although there have been many studies on departure time and crowding, few of them contributed to solve the following questions:

(i) How commuters in urban rail transit respond and change their risk attitudes to early and late arrivals when they face different extents of gains and losses

(ii) Whether all degrees of crowding have an influence on commuters' departure time choice and if so, how they influence

(iii) Whether passengers have taste variation on the influencing factors of departure time choice and if so, how the taste variation distributes

To address these questions, the paper puts forward a reference point-based valuation framework to capture commuters' responses to their arrival times, designs a combined RP and SP survey to reflect commuters' perceptions of their actual experiencing crowding, and finally 
explores how different impact crowding has on commuters who experience different degrees of crowding by using a mixed logit model.

The remainder of the paper is structured as follows: Section 2 introduces the model framework and model specification. The survey design and data description are detailed in Section 3. The results are discussed in Section 4. And Section 5 summarises the findings and suggests directions for future research.

\section{Methodology}

In urban rail transit, the departure time choice is mainly a trade-off between arrival time value and experienced crowding of passengers. Therefore to understand how passengers value their arrival times without the influence of crowding is a prior condition for establishing a departure time choice model for urban railway commuters. Thus, we will firstly build a submodel of arrival time valuation and pass its output to the main model of departure time choice.

\subsection{Submodel: Arrival Time Valuation Model. We intro-} duced the reference point approach of prospect theory [52] to describe urban rail commuters' reactions to different arrival times. In the prospect theory, a commuter is assumed to maintain the same departure time as long as his/her actual arrival time is within an indifference band; otherwise, the commuter will adjust his/her departure time through some procedures [52, 53]. This assumption still holds when crowding impact is not taken into account, and commuters only compare different departure time alternatives by their values. With this approach, actual arrival time (AAT) is valued according to its deviation from reference points, instead of its absolute value. The reference points include two demarcation points of the indifference band, one for too-early arrival time (EAT) and the other for too-late arrival time (LAT), and optimal arrival time (OAT). Based on the assumption, a commuter's choice of switching his/her departure time or not is devised as a binary probit model, the utility of which is the sum of arrival time value and random error. When the utility of arrival time is greater than zero, the commuter will keep the same choice, otherwise, switch to a new one, as shown in the following equations:

$$
\begin{gathered}
p(N S)=p(d=1)=p\left(U\left(t_{a}\right)>0\right)=p\left(V\left(t_{a}\right)+\varepsilon>0\right), \\
p(S)=p(d=0)=p\left(U\left(t_{a}\right)<0\right)=p\left(V\left(t_{a}\right)+\varepsilon<0\right),
\end{gathered}
$$

where $p(N S)$ is the probability of not switching departure time, $p(S)$ is the probability of switching departure time, $U\left(t_{a}\right)$ is the utility of arrival time, $V\left(t_{a}\right)$ is the arrival time value, $\varepsilon$ is the random error, $d=1$ if a commuter maintains his/her departure time, and $d=0$, otherwise.

Three valuation frameworks were developed to describe the behaviour patterns of commuters in urban rail transit based on the previous work of Cheng et al. [54]. Arrival time itself is continuous, but its value is influenced by which area it falls in. The proposed frameworks involved one or both kinds of reference points.

Framework A: commuters value their arrival times according to the demarcation points of indifference band [55]. The demarcation points of too-early arrival and too-late arrival are reference points with zero values, and optimal arrival time is a "pseudo" reference point with maximum value to define early-side and late-side arrival. The utility function is shown as follows:

$$
U_{A}\left(t_{a}\right)=V_{A}\left(t_{a}\right)+\varepsilon= \begin{cases}c_{1}+\beta_{1}\left(t_{E}-t_{a}\right)^{\alpha_{1}}+\varepsilon_{e}^{L} & \left(t_{d}<t_{a} \leq t_{E}\right), \\ c_{1}+\beta_{2}\left(t_{a}-t_{E}\right)^{\alpha_{2}}+\varepsilon_{e}^{G} & \left(t_{E}<t_{a} \leq t_{O}\right), \\ c_{2}+\beta_{3}\left(t_{L}-t_{a}\right)^{\alpha_{3}}+\varepsilon_{l}^{G} & \left(t_{O}<t_{a}<t_{L}\right), \\ c_{2}+\beta_{4}\left(t_{a}-t_{L}\right)^{\alpha_{4}}+\varepsilon_{l}^{L} & \left(t_{a} \geq t_{L}\right) .\end{cases}
$$

Framework B: commuters value their arrival times only according to optimal arrival time. Optimal arrival time is the only reference point, at which arrival time value reaches the maximum. The value decreases with the increase of difference between actual arrival time and optimal arrival time:

$$
U_{B}\left(t_{a}\right)=V_{B}\left(t_{a}\right)+\varepsilon= \begin{cases}\gamma_{1}+\beta_{5}\left(t_{O}-t_{a}\right)^{\alpha_{5}}+\varepsilon_{e} & \left(t_{d}<t_{a} \leq t_{O}\right), \\ \gamma_{1}+\beta_{6}\left(t_{a}-t_{O}\right)^{\alpha_{6}}+\varepsilon_{l} & \left(t_{a}>t_{O}\right) .\end{cases}
$$

Framework C: commuters value their arrival times according to optimal arrival time when they are early-side arrivals and value their arrival time according to the demarcation point of too-late arrival when they are late-side arrivals:

$$
U_{C}\left(t_{a}\right)=V_{C}\left(t_{a}\right)+\varepsilon= \begin{cases}\gamma_{2}+\beta_{7}\left(t_{O}-t_{a}\right)^{\alpha_{7}}+\varepsilon_{e} & \left(t_{d}<t_{a} \leq t_{O}\right), \\ c_{2}+\beta_{8}\left(t_{L}-t_{a}\right)^{\alpha_{8}}+\varepsilon_{l}^{G} & \left(t_{O}<t_{a}<t_{L}\right), \\ c_{2}+\beta_{9}\left(t_{a}-t_{L}\right)^{\alpha_{9}}+\varepsilon_{l}^{L} & \left(t_{a} \geq t_{L}\right) .\end{cases}
$$

In the above equations, $t_{d}$ is the departure time, $t_{a}$ is the actual arrival time, $t_{O}$ is the optimal arrival time, $t_{E}$ is the demarcation point of too-early arrival, and $t_{L}$ is the demarcation point of too-late arrival. The error terms are assumed to be normally distributed with zero means and heteroskedastic variances under various circumstances. They are distinguished by subscripts and superscripts. The subscript $e$ represents the early side and $l$ represents the late side, and the superscripts $G$ and $L$ represent gain and loss, respectively. Parameters $\alpha_{i}(i=1, \ldots, 9)$ represent the rates of changes in value to the commuter. The values of $\alpha_{i}(i=1, \ldots$, 9) are not predetermined in this research because whether the segments of functions are convex or concave needs to be decided based on estimation result. However, exponents should be greater than 0 because, otherwise, the curve would tend towards infinity at each reference point, which conflicts with the basic theory. Parameters $\beta_{i}(i=1, \ldots, 9)$ are weights which represent the importance of value in different segments to the commuter. According to the frameworks, except $\beta_{2}, \beta_{3}$, and $\beta_{8}$, the other $\beta_{s}$ should take on negative values. Parameters $\gamma_{i}(i=1,2)$ are the values of the optimal 
arrival time within frameworks $\mathrm{B}$ and $\mathrm{C}$, which should be positive. Parameters $c_{1}$ and $c_{2}$ are set to regulate the potential deviations between the surveyed demarcation points of tooearly and too-late arrival and their real values.

Several alternative time points were chosen to represent each kind of reference point, which are given in Table 1. The best arrival time valuation framework was decided by comparing the performances of three abovementioned frameworks with the combinations of different reference point alternatives.

\subsection{Main Model: Departure Time Choice Model}

2.2.1. Theoretical Background. Given that commuters have considerably fixed destination arrival times [56], who are supposed to be little influenced by other activities, and the travel time reliability of rail transit is much higher than road traffic, this paper develops a schedule model to describe the departure time choice of commuters in urban rail transit. Logit models were firstly established to test whether all degrees of crowding have an impact on departure time choice and how to define effective crowding. A specification test was then carried out to statistically test whether mixing is needed for the discrete choice model. A mixed logit model was built with the distributions of the random parameters being decided based on their empirical distributions.

We assume that commuters' departure time choice complies with utility maximization theory when crowding impact is taken into consideration, that is, when a commuter faces several alternative departure time choices, he/she will choose the one that provides the greatest utility. The utility has two components, one is the representative utility which includes the influence of explanatory factors that can be observed, and the other one is the random error which captures the factors that affect the utility but are not included in the representative utility, as shown in the following equation:

$$
U_{\text {in }}=V_{\text {in }}+\varepsilon_{\text {in }}, \quad n=1, \ldots, N ; i=1, \ldots, J_{n},
$$

where $U_{\text {in }}$ is the utility of alternative $i$ for commuter $n, V_{i n}$ is the representative utility of alternative $i$ for commuter $n, \varepsilon_{i n}$ is the random error of alternative $i$ for commuter $n, N$ is the total number of commuters, and $J_{n}$ is the number of alternatives for commuter $n$. In classical logit models, the distribution of each random error is assumed to be independent and identically extreme value type I distributed, also known as Gumbel distribution. The choice probability of commuter $n$ to choose alternative $i$ in a logit model is given by

$$
P_{\text {in }}=\frac{e^{V_{\text {in }}}}{\sum_{j} e^{V_{\text {jn }}}}, \quad i, j=1, \ldots, J_{n} ; n=1, \ldots, N .
$$

The independence from irrelevant alternatives (IIA) property of choice probabilities leads to one limitation of logit models that they cannot represent random taste variation. In other words, the value or importance that commuters place on each attribute of the alternative does not vary over commuters but fixed. Due to the differences in subjective perception and experienced crowding for each commuter, it is arbitrary to accept this specification. Mixed logit [57] could obviate this limitation through the relaxation of the IIA property. The taste variation is considered in the utility of commuters shown in the following equation:

$$
U_{\text {in }}=\boldsymbol{\beta}_{\mathbf{n}}^{\prime} \mathbf{x}_{\mathrm{in}}+\varepsilon_{i n}
$$

where $\mathbf{x}_{\mathbf{i n}}$ is a $1 \times M$ vector of observed variables that relate to the alternative $i$ and commuter $n$ and $\beta_{\mathbf{n}}$ is a $M \times 1$ vector of parameters of variables for commuter $n$ representing his/her tastes. The parameters vary over commuters in the population with density $f(\boldsymbol{\beta} \mid \boldsymbol{\theta})$, which can be assumed as a specific kind of distribution, such as normal, lognormal, and uniform distribution. The choice probabilities of mixed logit model are the integrals of standard logit probabilities over possible variables of $\boldsymbol{\beta}_{\mathbf{n}}$, which can be expressed as follows:

$$
\begin{gathered}
P_{\text {in }}=\int L_{\text {in }}\left(\boldsymbol{\beta}_{\mathbf{n}}\right) f(\boldsymbol{\beta} \mid \boldsymbol{\theta}) \mathrm{d} \beta, \\
L_{\text {in }}\left(\beta_{n}\right)=\frac{\exp \left(\boldsymbol{\beta}_{\mathbf{n}}^{\prime} \mathbf{x}_{\mathbf{i n}}\right)}{\sum_{j} \exp \left(\boldsymbol{\beta}_{\mathbf{n}}^{\prime} \mathbf{x}_{\mathbf{j n}}\right)}, \quad i, j=1, \ldots, J_{n} ; n=1, \ldots, N,
\end{gathered}
$$

where $L_{\text {in }}\left(\boldsymbol{\beta}_{\mathbf{n}}\right)$ is the logit probability of alternative $i$ for commuter $n$ evaluated at parameters $\boldsymbol{\beta}_{\mathbf{n}}, f(\boldsymbol{\beta} \mid \boldsymbol{\theta})$ is the density function of $\boldsymbol{\beta}$ that varies over commuter in the population with the parameter vector $\boldsymbol{\theta}$. Instead of the parameter vector $\boldsymbol{\beta}$ itself, the parameter vector $\boldsymbol{\theta}$ that describes the density of parameter $\beta$ is to be estimated in a mixed logit model.

Although the mixed logit has the advantage of representing taste variation, whether mixing is needed for the parameters of variables should be tested statistically. The test proposed in McFadden and Train [57] was used to accept or reject the preservation of fixed parameters in the model. Suppose the alternatives are from a set $C=\left\{1, \ldots, J_{n}\right\}, \mathbf{x}_{\mathbf{i}}$ is a $1 \times M$ vector of variables of alternative $i$, and $N$ is the total number of commuters. The test estimates the parameter $\alpha$ in the classical multinomial logit model by using maximumlikelihood method and then constructs artificial variables for selected components $t$ of $\mathbf{x}_{\mathbf{i}}$ as in the following equations:

$$
\begin{aligned}
z_{\text {tin }}= & 0.5\left(x_{t i n}-x_{t C n}\right)^{2}, \\
& t=1, \ldots, M ; i=1, \ldots, J_{n} ; n=1, \ldots, N, \\
x_{t C n}= & \sum_{j} x_{t j n} P_{j n}=\frac{\sum_{j} x_{t j n} \cdot \exp \left(\widehat{\boldsymbol{\alpha}}_{\mathbf{n}}^{\prime} \mathbf{x}_{\mathbf{j n}}\right)}{\sum_{j \in C} \exp \left(\widehat{\boldsymbol{\alpha}}_{\mathbf{n}}^{\prime} \mathbf{x}_{\mathbf{j n}}\right)},
\end{aligned}
$$

where $x_{\text {tin }}$ is the variable of the component $t$ from variables vector $\mathbf{x}_{\mathbf{i}}$ of alternative $i$ for commuter $n, x_{t C n}$ is a weighted sum of $x_{t i n}, P_{j n}$ is the choice probabilities of commuter $n$ to choose alternative $j$, and $\widehat{\alpha}_{n}$ is the maximum-likelihood estimates of multinomial logit model. The logit model is then reestimated including these artificial variables, and the null hypothesis of no random parameters on attributes $x$ is rejected if the parameters of the artificial variables are significantly different from zero. The actual test for the joint 
TABLE 1: Alternatives for each reference point.

\begin{tabular}{lc}
\hline Reference point & Alternatives \\
$\begin{array}{l}\text { The demarcation point of too-early arrival (EAT) } \\
\text { The demarcation point of too-late arrival (LAT) }\end{array}$ & $\begin{array}{c}\text { The acceptable earliest arrival time (AEAT) } \\
\text { Work/school start time (WST) }\end{array}$ \\
\hline The time when a commuter starts to consider departing later (SCDLT)
\end{tabular}

significance of the $z$ variables can be carried out using a Wald test statistic. This test is asymptotically equivalent to a Lagrange multiplier test of the hypothesis of no mixing against the alternative of a mixed logit model with mixing in the selected components $t$ of $\alpha$.

Once whether a parameter is random or not is decided, a "jackknife" resampling procedure will be used to explore the empirical distribution of a parameter. With this procedure, $Q+1$ models are to be estimated, with $Q$ as the number of individuals included [58]. Except for a model involving the entire sample, each of the other models is distinguished by removing a different individual. The profile of individual preference heterogeneity can be reflected by observing the difference in the numerical value of the parameter estimates of these $Q+1$ models.

2.2.2. Utility Function. In the context of urban rail transit, we assume services are with sufficiently high frequency, usually with expected waiting time less than $3 \mathrm{~min}$. In this case, when passengers change their departure time, they do not need to take timetables into consideration.

Although departure time itself is continuous, we found that most of the commuters change their times in a granularity of $5 \mathrm{~min}$ (Section 3) within a limited range. Theoretically, commuters could change their departure times to whatever extent; however, the time out of acceptable ranges does not make practical sense. For these reasons, we discretised the departure time choices into 13 alternatives according to our case, i.e., commuters can choose from departing earlier or later than their original departure times from $5 \mathrm{~min}$ to $30 \mathrm{~min}$ with $5 \mathrm{~min}$ as the interval or keeping the same. The span of range may slightly vary from case to case, but the finite alternative set should be exhaustive.

According to the previous studies, we can conclude the main trade-off in departure time choice is between arrival time value and experienced crowding. Besides, when a commuter has chosen one departure time before, he/she would be unwilling to switch to a new departure time in the next trip because of the uncertainty that a change may cause. For this reason, the utility of a specific departure time choice of a commuter in urban rail transit includes three parts: the reluctance to switch departure time, crowding impact, and arrival time impact, as shown in the following equation:

$$
\begin{array}{r}
U\left(t_{d_{i n}}\right)=\lambda_{e} \delta_{e_{i}}+\lambda_{l} \delta_{l_{i}}+\sum_{k \in K} \lambda_{c_{k}} t c_{k i n}+\lambda_{a} V\left(t_{a_{i n}}\right)+\varepsilon_{i n}, \\
i=0, \ldots, 12 ; n=1, \ldots, N,
\end{array}
$$

where $t_{d_{i n}}$ is the $i_{t h}$ departure time alternative for commuter $n$, when $i=0$, the alternative is the original departure time, $t_{a_{i n}}$ is the corresponding arrival time of $t_{d_{i n}}$, and $U\left(t_{d_{i n}}\right)$ is the utility of $t_{d_{i n}}$. $\delta_{e_{i}}$ and $\delta_{l_{i}}$ are dummy variables indicating whether $t_{d_{\text {in }}}$ is earlier or later than the original departure time, $\delta_{e_{i}}=1$ if $t_{d_{i n}}>t_{d_{0 n}}$ while $\delta_{l_{i}}=1$ if $t_{d_{i n}}<t_{d_{0 n}}$, and otherwise, both variables are equal to zero. $t c_{k i n}$ is the crowding cost with the grade of crowding being $k . K$ is the set of grades of effective crowding that has an impact on the departure time choice of commuters. $V\left(t_{a_{\text {in }}}\right)$ is the arrival time value of $t_{a_{i n}} . \varepsilon_{i n}$ is the random error of the $i$ th departure time alternative for commuter $n$, which is assumed to be Gumbeldistributed. $\lambda$ 's are parameters to be estimated. Whether they are random parameters or not needs to be tested. It is worth noting that the fare is fixed for the same origin-destination station pair regardless of which route a commuter chooses in our case study, and the influence of fare, therefore, was not included.

In the utility function, two dummy variables were assigned to indicate whether the alternative departure time is earlier or later than the original departure time, which is analogous to the nests in a nested logit model. The parameters of both variables represented the reluctances of commuters to change their original departure time to either early or late side. Generally, the parameters $\lambda_{e}$ and $\lambda_{l}$ are supposed to be negative. The total crowding impact on commuters' departure time choice was quantified as a weighted sum of all effective crowding costs. Because the commuters' perceptions of crowding are shaped by their subjective feelings of the surrounding environment, mainly through observing in-vehicle occupancy situation and their physical contact with others, which is bound to be vague and inaccurate, so the degrees of crowding were divided into finite grades rather than continuous value. Considering the realism of crowding degrees and the cognitive burden for respondents in survey, a five-grade scale was established according to the ratio of passengers sitting and standing and whether there is physical contact or even squeezing with others, as shown in Table 2. Occupancy rate, the ratio of passenger number to capacity of each vehicle, was used to quantitatively represent the different grades. Corresponding occupancy rate range was estimated based on the vehicle configuration of our case study, Shanghai Metro. The representative occupancy rates were the mean occupancy rates for Grade 1 to Grade 4, while 100\% for Grade 5 because in that case the actual occupancy rate may sometimes exceed $100 \%$. For each grade of crowding, the crowding cost $t c_{k i n}$ was calculated by multiplying the representative occupancy 
TABLE 2: The grading of crowding.

\begin{tabular}{lccc}
\hline Grade & $\begin{array}{c}\text { Occupancy rate } \\
\text { range (\%) }\end{array}$ & $\begin{array}{c}\text { Representative occupancy } \\
\text { rate (\%) }\end{array}$ & Description \\
\hline 1 & $0-20$ & 10 & $\begin{array}{c}\text { All passengers in vehicle have seats } \\
\text { Most of the passengers in vehicle have seats, while a small number of passengers } \\
\text { have to stand }\end{array}$ \\
3 & $20-40$ & 30 & $\begin{array}{c}\text { A majority of passengers in vehicle have to stand, but there is no physical contact } \\
\text { A majority of passengers in vehicle have to stand with physical contact, but there } \\
\text { is no squeezing }\end{array}$ \\
4 & $40-80$ & 60 & $\begin{array}{c}\text { A majority of passengers in vehicle have to stand with intense squeezing or the } \\
\text { passengers waiting on platform cannot board on train }\end{array}$ \\
\hline
\end{tabular}

rate of that grade by its corresponding in-vehicle time to reflect the extra travel time caused by crowding. This is because the main effect of crowding is magnifying the perceived in-vehicle time of passengers, so the crowding effect is influenced not only by the degree of crowding, but also by the duration of the corresponding degree of crowding. Meanwhile, this crowding valuation method has been proved to be more transferrable across different contexts [8]. The weight $\lambda_{c_{k}}$ is the unit impact of crowding cost of each effective crowding, which is assumed to be negative. Whether a grade of crowding is effective needs to be discussed further.

\section{Survey Design and Data}

3.1. Survey Design. To better understand how commuters make a trade-off between their arrival time values and crowding, an innovative survey combining revealed preference (RP) questions and stated preference (SP) experiments was specifically designed. The survey consisted of four parts in Table 3, with the first part collecting the socioeconomic characteristics and metro usage information of respondents, the second part exploring commuters' latent attitudes to potential arrival times, the third part investigating their actual routes and the corresponding grades of crowding, and the last part focusing on whether and how they will switch departure time when the grade of crowding changes. To avoid the bias caused by different perceptions of crowding, the grading of crowding was clearly set out graphically and in written explanation in survey.

The survey asked respondents twice about the willingness to switch departure time, respectively, without and with crowding situation change. The first answer was used for estimating the arrival time valuation model, while the second one was for investigating in what manner and to what extent commuters adjust their departure times. Different from repeating the same question several times with distinct configurations in most of traditional SP survey, our survey adopted an innovative way by asking a set of RP-based progressive questions. Respondents were first asked whether they are willing to switch their departure times in their first metro trip on next weekday when the crowding of the most crowded part they experienced in the first trip on the latest weekday degrades by one level, with no change to the duration. For example, if the original grade of crowding of the most crowded part for one respondent was Grade 5, then the one after change would be Grade 4 . If they chose to switch, a further question would follow up to ask whether they will depart earlier or later. After they decided the manner of switching, the extent of switching departure time was raised by asking them how much time at most they can accept to change from their original departure times. These SP questions were customised according to the answers in the third part based on respondents' actual experiences and revealed preferences, trying to avoid the distortion of their perceptions caused by fatigue in answering similar questions with scenarios far away from their situations. The design tried to avoid that respondents' answers are mixtures of learning and inertia effects caused by the sequencing of offered choice situations. It is noteworthy to mention here that only the grade of crowding of the most crowded part being changed has twofold reasons. One is the survey needed to control variables to figure out the impact of different grades of crowding, and the other is passengers were assumed to have the deepest impression of the extreme situation, say, the most crowded part.

Because of the distinct design of the question asking the willingness of commuters to switch departure time when crowding changes, each commuter's answer can be converted to at least one choice situation. It is because commuters were asked how much time at most they can accept to change from their original departure times, which means if there were an alternative (available) that requires a smaller change than their answers, they would choose that alternative. If more than one alternative less than their answers are available, they would choose the one with the smallest change. State equivalently, commuters were assumed to choose the least extent of change within the range of change extent they answered when it is available. If all the available alternatives are beyond the range of change extent they answered, commuters would choose to keep the original departure times. The number of choice situations, therefore, is equal to $\left\lceil\Delta t_{a c} / 5\right\rceil+1$, where $\Delta t_{a c}$ is the acceptable extent of change for a commuter and the symbol $\lceil\cdot\rceil$ means the ceiling of the number. For all the choice situations, if a commuter chooses to depart earlier or later, the other side would be available for him/her all the time.

3.2. Data Collection and Description. Data were collected through a web-based interactive questionnaire between June 2017 and August 2017 with the help of an online survey 
TABLE 3: The combined RP and SP survey.

\begin{tabular}{|c|c|c|}
\hline Part & Questions & Method \\
\hline Basic information & $\begin{array}{c}\text { Gender } \\
\text { Age } \\
\text { Occupation }\end{array}$ & \\
\hline Arrival time valuation & $\begin{array}{c}\text { Work/school start time } \\
\text { Preparation time before work/school start time } \\
\text { Preferred arrival time } \\
\text { The acceptable earliest arrival time } \\
\text { The acceptable latest arrival time } \\
\text { The time when he/she starts to consider departing later next time } \\
\text { The time when he/she starts to consider departing earlier next time } \\
\text { The actual departure time of the first metro trip on the latest weekday } \\
\text { The actual arrival time of the first metro trip on the latest weekday } \\
\text { The willingness to switch departure time according to the arrival time of the first } \\
\text { metro trip on the latest weekday }\end{array}$ & $\begin{array}{l}\text { RP } \\
\text { SP } \\
\text { SP } \\
\text { SP } \\
\text { SP } \\
\text { SP } \\
\text { SP } \\
\text { RP } \\
\text { RP } \\
\text { SP }\end{array}$ \\
\hline Crowding valuation & $\begin{array}{l}\text { The actual route choice of the first metro trip on the latest weekday } \\
\text { The grade of crowding of the most crowded part on the route } \\
\text { The duration of the most crowded part on the route }\end{array}$ & $\begin{array}{l}\text { RP } \\
\text { RP } \\
\text { RP }\end{array}$ \\
\hline $\begin{array}{l}\text { Willingness to switch departure time when } \\
\text { crowding changes }\end{array}$ & $\begin{array}{c}\text { The willingness to switch departure time if crowding situation changes in the first } \\
\text { metro trip on next weekday } \\
\text { The manner of switching departure time } \\
\text { The extent of switching departure time }\end{array}$ & $\begin{array}{l}\text { SP } \\
\text { SP } \\
\text { SP }\end{array}$ \\
\hline
\end{tabular}

system. The link was emailed to around 1400 people who register to live in Shanghai in the system. To ensure the respondents are the commuters in Shanghai Metro who use rail transit system frequently, all respondents needed to pass a screening procedure. The first step was carried out before each respondent entering the questionnaire. Two questions, whether the respondent lives in Shanghai and uses Shanghai Metro per week, were asked to examine whether the respondent was eligible to get in the body of the questionnaire. However, the second step was after their completion of the survey, in which manual double check was executed to guarantee they were targets by reviewing their frequencies of using Shanghai Metro and their purposes of the first metro trip on the latest weekday. After passing this procedure, all the questionnaires went to the final validity check, which tested whether there were answers missing, inconsistent, or incorrect (e.g., the name of the metro station or the interchange station on the route). Note that the survey plan and designs have been approved by Tongji University (ref: 35744).

The study of arrival time valuation only required the data of parts 1 and 2 to be valid whilst the one of departure time choice model including crowding impact required the data from all parts to be valid. In the light of this, to make the best use of the survey data, 585 questionnaires got through all tests and served for arrival time valuation, of which 460 questionnaires were extracted to be used in the estimation of departure time choice model. It is worth mentioning that to ensure commuters who switch their departure time choice when being asked the second time were solely because of the change of crowding, only those who did not switch departure times when there was no change of crowding were eligible. Table 4 summarises the socioeconomic and travel characteristics of both samples. A large majority of respondents travelled by metro more than 3 times in one week with the purpose of going to work/school, which suggests that they were commuters familiar with Shanghai Metro network.

The work/school start times of most of the respondents ranged from 7:30 to 9:30 am (96.24\%). A majority of respondents started work/school at 9:00 am (49.06\%), followed by $8: 30$ am $(23.42 \%)$, as shown in Figure 1 . The statistics of time points related to arrival time valuation of urban rail transit commuters surveyed are shown in Table 5. The analysis of variance (ANOVA) result in Table 6 shows that except the difference between work/school start time and the time when a commuter starts to consider departing earlier, all the others between alternative reference points were significant at the $5 \%$ level.

Table 7 gives the distribution of the grades of crowding of the most crowded part experienced by 460 commuters in Shanghai Metro. More than $70 \%$ of them experienced the crowding with physical contact with others in vehicle. Furthermore, $40 \%$ of respondents had to bear being squeezed.

223 respondents $(48.48 \%)$ chose to keep the same departure times while 222 chose to depart earlier (48.26\%). Only 15 respondents (3.26\%) preferred to depart later. Figure 2 presents the willingness of respondents to switch their departure time choices when the grades of crowding of the most crowded part degrade by one level. The respondents experiencing original crowding of Grade 5 tended to depart earlier or later most $(57.05 \%)$, whereas none of the ones experiencing original crowding of Grade 1 was going to switch their departure times. Although there was no big 
TABle 4: Respondents's socioeconomic and metro usage profile.

\begin{tabular}{|c|c|c|c|c|}
\hline \multirow{2}{*}{ Items } & \multicolumn{2}{|c|}{ Arrival time valuation } & \multicolumn{2}{|c|}{ Departure time choice } \\
\hline & $N$ & $\%$ & $N$ & $\%$ \\
\hline \multicolumn{5}{|l|}{ Gender } \\
\hline Male & 266 & 45.47 & 209 & 45.43 \\
\hline Female & 319 & 54.53 & 251 & 54.57 \\
\hline \multicolumn{5}{|l|}{ Age } \\
\hline$<18$ & 10 & 1.71 & 7 & 1.52 \\
\hline $18-40$ & 513 & 87.69 & 399 & 86.74 \\
\hline $41-60$ & 61 & 10.43 & 53 & 11.52 \\
\hline$>60$ & 1 & 0.17 & 1 & 0.22 \\
\hline \multicolumn{5}{|c|}{ The frequency of travelling by metro per week } \\
\hline $1-2$ times & 61 & 10.43 & 47 & 10.72 \\
\hline$>3$ times & 524 & 89.57 & 413 & 89.78 \\
\hline \multicolumn{5}{|c|}{ The time period of travelling by metro per week } \\
\hline Only weekdays & 163 & 27.86 & 133 & 28.91 \\
\hline Weekdays and weekends & 422 & 72.14 & 327 & 71.09 \\
\hline \multicolumn{5}{|c|}{ The purpose of the first metro trip on the latest weekday } \\
\hline Work & 568 & 97.09 & 449 & 97.61 \\
\hline School & 17 & 2.91 & 11 & 2.39 \\
\hline Total & 585 & 100 & 460 & 100 \\
\hline
\end{tabular}

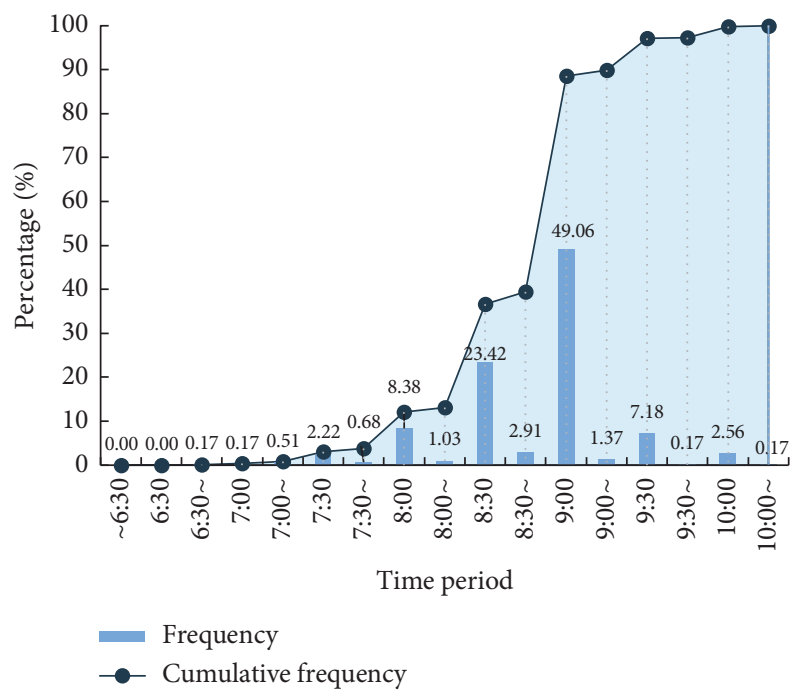

FIgURE 1: The distribution of work/school start time.

TABLE 5: Time points related to arrival time valuation.

\begin{tabular}{|c|c|c|c|c|}
\hline Time point & Mean & Min & Max & Std. deviation (min) \\
\hline The acceptable earliest arrival time (AEAT) & $8: 24$ & $6: 20$ & $9: 55$ & 33.43 \\
\hline The time when a commuter starts to consider departing later (SCDLT) & $8: 18$ & $6: 30$ & $9: 50$ & 33.03 \\
\hline Preferred arrival time at workplace/school (PAT) & $8: 38$ & $6: 35$ & $10: 00$ & 30.80 \\
\hline Work/school start time (WST) & $8: 48$ & $6: 45$ & $10: 30$ & 29.85 \\
\hline The acceptable latest arrival time (ALAT) & $8: 55$ & $6: 45$ & $11: 00$ & 32.83 \\
\hline The time when a commuter starts to consider departing earlier (SCDET) & $8: 51$ & $6: 45$ & $10: 40$ & 32.76 \\
\hline
\end{tabular}

difference in the proportions of commuters being willing to switch departure times among the commuters experiencing original crowding of Grades 4 to 2, there did exist a big difference in the extents of switching departure time.

Table 8 shows for the group of respondents who were willing to switch departure times for degraded crowding, and those who experienced crowding of Grades 3 and 2 were more willing to adjust their departure times within a short range. The time adjustments of more than $80 \%$ of them were less than or equal to $10 \mathrm{~min}$. In contrast, those who experienced crowding of Grades 5 and 4 were more likely to change their departure times farther away from the original 
TABLE 6: The differences between alternative reference points of arrival time valuation.

\begin{tabular}{|c|c|c|c|c|c|c|}
\hline \multirow{2}{*}{ Difference (min) } & \multicolumn{2}{|c|}{ ANOVA } & \multirow{2}{*}{ Mean } & \multirow{2}{*}{ Min } & \multirow{2}{*}{ Max } & \multirow{2}{*}{ Std. deviation } \\
\hline & $F$ & Sig. & & & & \\
\hline SCDLT-AEAT & 8.784 & $0.003^{* *}$ & -5.76 & -60.00 & 70.00 & 12.05 \\
\hline WST-PAT & 32.555 & $0.000^{* * *}$ & 10.12 & 0.00 & 50.00 & 5.99 \\
\hline ALAT-WST & 15.691 & $0.000^{* * *}$ & 7.27 & 0.00 & 90.00 & 10.23 \\
\hline SCDET-WST & 3.189 & $0.074^{*}$ & 3.27 & -20.00 & 60.00 & 11.12 \\
\hline SCDET-ALAT & 4.314 & $0.037^{* *}$ & -3.99 & -70.00 & 45.00 & 11.06 \\
\hline
\end{tabular}

Note. ${ }^{*}$ Difference is significant at the $10 \%$ level. ${ }^{* *}$ Difference is significant at the $5 \%$ level. ${ }^{* * *}$ Difference is significant at the $1 \%$ level. SCDLT: the time when a commuter starts to consider departing later; AEAT: the acceptable earliest arrival time; WST: work/school start time; PAT: preferred arrival time at workplace/school; ALAT: the acceptable latest arrival time; SCDET: the time when a commuter starts to consider departing earlier.

TABLE 7: The distribution of the grade of crowding of the most crowded part.

\begin{tabular}{lccc}
\hline Original grade of crowding & $N$ & $\%$ & Avg. adjustment (min) \\
\hline Grade 5 & 191 & 41.52 & 6.79 \\
Grade 4 & 133 & 28.91 & 5.86 \\
Grade 3 & 103 & 22.39 & 5.37 \\
Grade 2 & 28 & 6.09 & 5.54 \\
Grade 1 & 5 & 1.09 & 0 \\
Total & $\mathbf{4 6 0}$ & $\mathbf{1 0 0}$ & $\mathbf{6 . 0 5}$ \\
\hline
\end{tabular}

Note. Avg. adjustment = total absolute adjustment/the number of respondents experiencing the same original grade of crowding. If one respondent keeps the same departure time, then adjustment is equal to zero.

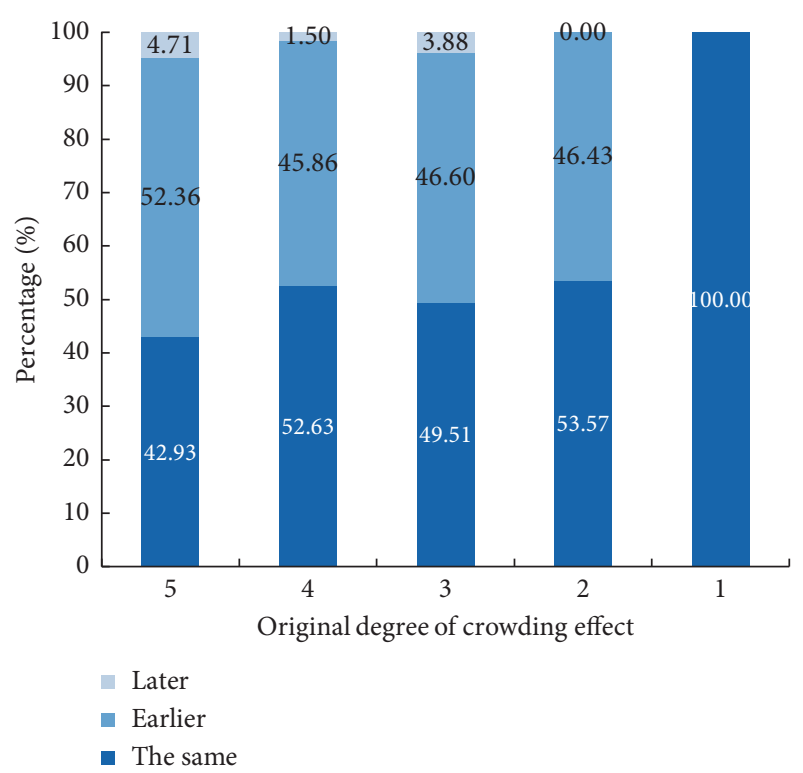

FIgURE 2: The willingness to switch departure time.

departure times. The commuters planning to depart earlier or later more than $10 \mathrm{~min}$ accounted for $29.00 \%$ for Grade 5 and $37.70 \%$ for Grade 4 . The analysis indicates that a higher grade of crowding may lead to an increase either in commuters' willingness to switch departure time or in their extents of adjustment.

\section{Results and Discussion}

4.1. Arrival Time Valuation Model. As a key component of departure time choice model, arrival time value needs to be firstly estimated without the influence of crowding cost. So the commuters' willingness to switch departure time without crowding situation change should be used to estimate this model. The arrival time value provides a basis for departure time choice model because it captures the pure attitudes of commuters towards different arrival times without any other impact. This helps to analyse the trade-off between arrival time value and crowding cost in the main departure time choice model, when the change of crowding situation is introduced. The economic and statistical significance tests were carried out on each estimation result to guarantee the signs of parameters are consistent with the proposed theory as well as the values of parameters are significant at the $5 \%$ level. For each valuation framework, only the estimation results passing two tests were picked out to be compared with each other. Since utility functions in arrival time valuation frameworks are nonlinear segmented functions, the assumption of normally distributed error terms would be broken if a logarithmic transformation is adopted. Thus, the parameters were estimated by combining maximum simulated likelihood with limited enumeration. Due to the properties of power function, the convexity of a function switches when exponent crosses 1 . Based on the significance test and predictive ability performances of models in a trial estimation, the value range of each exponent $\alpha$ was set to be $(0,2]$, with step size 0.05 . Table 9 shows that all the models within Framework A failed significance tests. Within Framework B, the models with work/school start time (WST) as optimal arrival time (OAT) were unable to pass significance tests. The best estimation came out when preferred arrival time at workplace/school (PAT) is the only reference point. Within Framework C, a model with preferred arrival time at workplace/school (PAT) and the time when a commuter starts to consider departing earlier (SCDET) as reference points had the best estimation result. More detailed estimation process could be found in a previous research [54]. 
TABLE 8: The distribution of the extent of switching departure time.

\begin{tabular}{|c|c|c|c|c|}
\hline \multirow[b]{2}{*}{ The extent of switching departure time } & \multicolumn{4}{|c|}{ Original grade of crowding } \\
\hline & $\begin{array}{c}\text { Grade } 5 \\
\%\end{array}$ & $\begin{array}{c}\text { Grade } 4 \\
\%\end{array}$ & $\begin{array}{c}\text { Grade } 3 \\
\%\end{array}$ & $\begin{array}{c}\text { Grade } 2 \\
\%\end{array}$ \\
\hline$(0,5]$ & 14.00 & 18.03 & 14.58 & 15.39 \\
\hline$(5,10]$ & 57.00 & 44.26 & 66.67 & 69.23 \\
\hline$(10,15]$ & 13.00 & 19.67 & 10.42 & 0.00 \\
\hline$(15,20]$ & 10.00 & 11.48 & 6.25 & 7.69 \\
\hline$(20,25]$ & 0.00 & 0.00 & 0.00 & 0.00 \\
\hline$(25,30]$ & 6.00 & 6.56 & 2.08 & 7.69 \\
\hline
\end{tabular}

TABLE 9: The best estimation results of three valuation frameworks.

\begin{tabular}{|c|c|c|c|c|c|c|c|c|c|c|c|}
\hline \multirow[b]{2}{*}{ Framework } & \multicolumn{3}{|c|}{ Reference points } & \multirow[b]{2}{*}{ Region } & \multirow[b]{2}{*}{ Parameter } & \multirow[b]{2}{*}{ Variable } & \multirow[b]{2}{*}{ Coefficient } & \multirow[b]{2}{*}{$T$-stat } & \multirow[b]{2}{*}{$\log L$} & \multirow[b]{2}{*}{$\rho^{2}$} & \multirow[b]{2}{*}{$\begin{array}{c}\text { Hit rate } \\
(\%)\end{array}$} \\
\hline & $\begin{array}{c}t_{E} \\
(\mathrm{EAT})\end{array}$ & $\begin{array}{c}t_{O} \\
(\mathrm{OAT})\end{array}$ & $t_{L}(\mathrm{LAT})$ & & & & & & & & \\
\hline A & \multicolumn{11}{|c|}{ None of the estimation results pass both economic and statistical significance tests } \\
\hline B & - & $t_{P}(\mathrm{PAT})$ & - & All arrivals & $\gamma_{1}$ & - & 2.255 & $10.349^{* * *}$ & -210.103 & 0.4819 & 85.64 \\
\hline & & & & & $\beta_{5}$ & $t_{O}-t_{a}$ & -0.384 & $-4.747^{* * *}$ & & & \\
\hline & & & & & $\beta_{6}$ & $t_{a}-t_{O}$ & -0.956 & $-7.349^{* * *}$ & & & \\
\hline & & & & & $\alpha_{5}$ & $t_{O}-t_{a}$ & 0.50 & - & & & \\
\hline & & & & & $\alpha_{6}$ & $t_{a}-t_{O}$ & 0.30 & - & & & \\
\hline \multirow[t]{8}{*}{ C } & \multirow[t]{8}{*}{ - } & \multirow[t]{8}{*}{$t_{P}(\mathrm{PAT})$} & \multirow[t]{8}{*}{$\begin{array}{c}t_{l 2} \\
(\mathrm{SCDET})\end{array}$} & \multirow[t]{3}{*}{$\begin{array}{c}\text { Early-side } \\
\text { arrivals }\end{array}$} & $\gamma_{2}$ & - & 2.153 & $9.464^{* * *}$ & -210.458 & 0.4809 & 85.13 \\
\hline & & & & & $\beta_{7}$ & $t_{O}-t_{a}$ & -0.311 & $-4.192^{* * *}$ & & & \\
\hline & & & & & $\alpha_{7}$ & $t_{O}-t_{a}$ & 0.55 & - & & & \\
\hline & & & & \multirow[t]{5}{*}{$\begin{array}{l}\text { Late-side } \\
\text { arrivals }\end{array}$} & $c_{2}$ & - & 0.383 & $2.634^{* * *}$ & & & \\
\hline & & & & & $\beta_{8}$ & $t_{L}-t_{a}$ & 0.044 & $2.658^{* * *}$ & & & \\
\hline & & & & & $\beta_{9}$ & $t_{a}-t_{L}$ & -0.087 & $-1.962^{* *}$ & & & \\
\hline & & & & & $\alpha_{8}$ & $t_{L}-t_{a}$ & 0.85 & - & & & \\
\hline & & & & & $\alpha_{9}$ & $t_{a}-t_{L}$ & 1.20 & - & & & \\
\hline
\end{tabular}

Notes. ${ }^{* *}$ Significant at the $5 \%$ level. ${ }^{* * *}$ Significant at the $1 \%$ level. $t_{E}$ : the demarcation point of too-early arrival (EAT); $t_{O}$ : the optimal arrival time $(\mathrm{OAT}) ; t_{L}$ : the demarcation point of too-late arrival (LAT); $t_{\mathrm{p}}$ : preferred arrival time at workplace/school (PAT); $t_{22}$ : the time when a commuter starts to consider departing earlier; $t_{a}$ : actual arrival time at workplace/school; $\gamma$ : the arrival time value of the optimal arrival time; $\beta$ : the weight of time difference between actual arrival time and corresponding reference point in each segment; $\alpha$ : the rate of change in value in each segment.

By comparing the estimation results of the best models of each framework, it is found that the optimal estimation result of Framework B performed the best, with both $\rho^{2}$ of 0.4819 and hit rate of $85.64 \%$ higher than Framework C, with $\rho^{2}$ of 0.4809 and hit rate of $85.13 \%$. The best models of Framework B are demonstrated in Figure 3 and equation (14), with preferred arrival time as the reference point:

$$
U_{B}\left(t_{a}\right)= \begin{cases}2.255-0.384\left(t_{O}-t_{a}\right)^{0.50}, & t_{d}<t_{a} \leq t_{O} \\ 2.255-0.956\left(t_{a}-t_{O}\right)^{0.30}, & t_{a}>t_{O}\end{cases}
$$

The result that the framework with optimal arrival time as the only reference point outperformed the others with two reference points leads us to believe that passengers do not evaluate their arrival times in a very complicated way. They would like to compare their arrival times with the same benchmark; either their arrivals are on early or late side. Furthermore, the optimal arrival time was represented by preferred arrival time, not work/school start time assumed in most of the existing literature studies, which provides evidence to our hypothesis that predetermining work/school start time as the desired arrival time of passengers does not reflect the reality. This finding suggests that the arrival time value of work/school start time is usually overestimated while the one of real optimal arrival time is underestimated. The result that passengers choose preferred arrival time, which is $10.12 \mathrm{~min}$ earlier than work/school start time on average in our case, as their reference point could be explained by the reason that commuters need a period of time to prepare for their daily work or adjust themselves to work mode in advance of the start of their work or school [59].

The result in Table 9 also shows that $\beta_{6}$ had a greater absolute value than $\beta_{5}$, which indicates that commuters responded asymmetrically to arrivals on early and late sides by attaching more disutility to being late. The time when arrival time value is equal to zero on late-arrival side was 17.46 min later than preferred arrival time, nearly half of the one on early-arrival side, $34.48 \mathrm{~min}$. The values of $\alpha_{5}$ and $\alpha_{6}$ statistically demonstrated that the value function was nonlinear. The curves in both quasi-gain regions were 


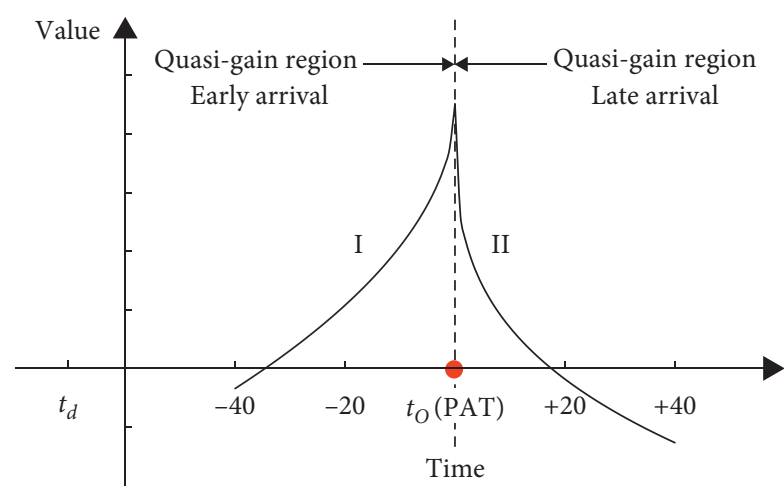

FIgURE 3: The optimal estimation result of Framework B.

convex, consistent with prospect theory. The result indicates that commuters showed varying attitudes to every unit of change instead of a fixed one in linear function. It also implies that commuters were risk-seeking no matter they arrived earlier or later than preferred arrival time, that is, they were willing to take big risks to increase the potential value of their arrival times. One explanation for this finding can be that commuters evaluate arrival time with respect to the decline from the gain at preferred arrival time, the reference point, which leads to the result that even though their arrival time value may be positive, they felt perceived losses.

4.2. Departure Time Choice Model. Except the five commuters who already experienced the least crowded situation (Grade 1) in our survey, 455 commuters were left for estimation. Thanks to the distinct design of question asking commuters' willingness to switch departure time when crowding changes, there were 1018 choice situations for estimation after the conversion. The conversion efficiently increased the size of estimation data without repeating asking commuters similar questions several times. All the models were estimated by using modified Matlab codes based on the ones developed by Train [60]. Note that the arrival time value for each choice situation was calculated according to the arrival time valuation model in Section 4.1.

The logit-based departure time choice models with different effective crowding specifications were estimated with maximum-likelihood method. The results in Table 10 show when the effective crowding covered all grades, the signs of all parameters were consistent with the qualitative analysis except $\lambda_{c_{1}}$, the weight of Grade 1 crowding cost, which was expected to be negative. Furthermore, the weight of Grade 2 failed the significance test at the $10 \%$ level. Both results point out that the Grade 1 and 2 crowding did not considerably contribute to the crowding impact on departure time choice of commuters. After removing them from the effective crowding set, all the parameters passed the economic and statistical significance tests and the model had a higher adjusted $\rho^{2} 0.409$. In both models, with or without the removal of Grade 1 and 2 crowding cost, the coefficients of Grade 3 to 5 crowding cost were negative and significant at the $1 \%$ level as all absolute values of $t$-statistics are larger
TABle 10: The estimates of logit-based departure time choice models with different effective crowding specifications.

\begin{tabular}{lcccc}
\hline Model & \multicolumn{2}{c}{$\begin{array}{c}\text { Logit with effective } \\
\text { crowding from Grade }\end{array}$} & \multicolumn{2}{c}{$\begin{array}{c}\text { Logit with effective } \\
\text { crowding from Grade }\end{array}$} \\
Parameter & Value & $T$-stat & Value & $T$ to 5 \\
\hline$\lambda_{e}$ & -0.906 & $-6.07^{* * *}$ & -0.845 & $-5.98^{* * *}$ \\
$\lambda_{l}$ & -4.898 & $-16.3^{* * *}$ & -4.831 & $-16.3^{* * *}$ \\
$\lambda_{c_{5}}$ & -0.098 & $-3.69^{* * *}$ & -0.077 & $-3.92^{* * *}$ \\
$\lambda_{c_{4}}$ & -0.088 & $-3.37^{* * *}$ & -0.066 & $-3.68^{* * *}$ \\
$\lambda_{c_{3}}$ & -0.088 & $-3.04^{* * *}$ & -0.061 & $-3.66^{* * *}$ \\
$\lambda_{c_{2}}$ & -0.045 & -1.11 & - & - \\
$\lambda_{c_{1}}$ & 0.050 & $2.22^{* *}$ & - & - \\
$\lambda_{a}$ & 1.201 & $16.8^{* * *}$ & 1.196 & $16.7^{* * *}$ \\
Log-likelihood & -1487.489 & & -1488.298 & \\
Adjusted $\rho^{2}$ & 0.408 & & 0.407 & \\
\hline
\end{tabular}

Note. ${ }^{* *}$ Significant at the $5 \%$ level. ${ }^{* * *}$ Significant at the $1 \%$ level. $\lambda_{e}$ : the reluctance to change original departure time to early side; $\lambda_{l}$ : the reluctance to change original departure time to late side; $\lambda_{c_{k}}(k=1-5)$ : the unit impact of crowding cost of Grade $k$ crowding; $\lambda_{a}$ : the unit impact of arrival time value.

than 2.58. This finding supports us to believe that Grade 3 to 5 crowding did impact on commuters' departure time choice, and not all degrees of crowding had an influence on departure time choice of commuters, which indicates that objective metrics could not represent commuters' subjective perceptions of crowding. The density-based indicators supposing that every degree of crowding impacts passengers' behavioural changes lack factual evidence. The reason why the boundary of effective crowding was between Grade 2 and Grade 3 could be attributed to the maintenance of a personal bubble. In the circumstances of Grade 2 crowding, although a part of commuters have to stand, their personal bubbles are guaranteed, while the crowding of Grade 3 or beyond is more likely to encroach their personal bubbles. This situation may result in qualitative changes in emotion and consideration about safety and security.

Based on this finding, all the parameters in the logit model with effective crowding ranging from Grades 3 to 5 were tested about whether mixing is needed. Table 11 shows that all the artificial variables constructed passed significance tests, which means that all of the parameters were random. A mixed logit was necessary for describing the taste variation of commuters on influencing factors.

With the help of resampling technique, 456 models were estimated to generate the estimates of six parameters. The histogram and kernel density distribution of each parameter are shown in Figure 4. According to the skewness and kurtosis characteristics, the distributions of parameters $\lambda_{e}$ and $\lambda_{a}$ can be assumed to be normally distributed. Although the distribution of parameter $\lambda_{l}$ had a long left-hand tail, its symmetrical pattern near the peak suggested it also can be assumed as a normal distribution. The distributions of parameters $\lambda_{c_{3}}, \lambda_{c_{4}}$, and $\lambda_{c_{5}}$ were more likely to be transformed lognormal distributions that have been moved over to the negative side. Three reasons that supported us to choose transformed lognormal distributions are as follows: (1) the empirical distributions had asymmetrical patterns near the 
TABLE 11: Specification test for all the parameters in the departure time choice model.

\begin{tabular}{lccc}
\hline Artificial variable & Value & Standard error & $T$-stat \\
\hline$\lambda_{e}$ & 13.940 & 0.747 & $18.66^{* * *}$ \\
$\lambda_{l}$ & 107.161 & 28.275 & $3.79^{* * *}$ \\
$\lambda_{c_{5}}$ & 0.005 & 0.002 & $2.71^{* * *}$ \\
$\lambda_{c_{4}}$ & -0.005 & 0.002 & $-2.29^{* *}$ \\
$\lambda_{c_{3}}$ & 0.010 & 0.004 & $2.71^{* * *}$ \\
$\lambda_{a}$ & -2.197 & 0.260 & $-8.46^{* * *}$ \\
\hline
\end{tabular}

Note. ${ }^{* *}$ Significant at the $5 \%$ level. ${ }^{* * *}$ Significant at the $1 \%$ level. $\lambda_{e}$ : the reluctance to change original departure time to early side; $\lambda_{l}$ : the reluctance to change original departure time to late side; $\lambda_{c_{k}}(k=1-5)$ : the unit impact of crowding cost of Grade $k$ crowding; $\lambda_{a}$ : the unit impact of arrival time value.
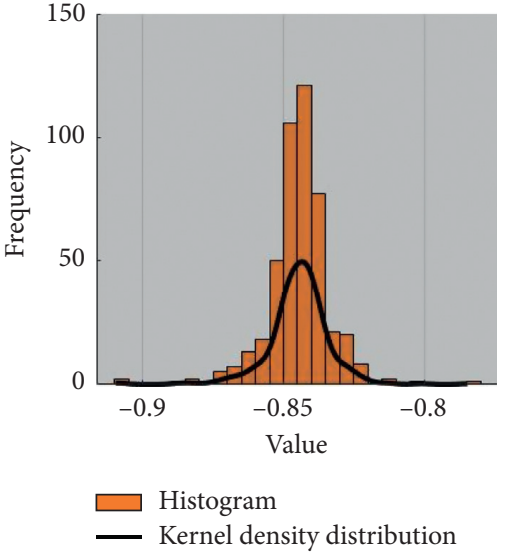

(a)

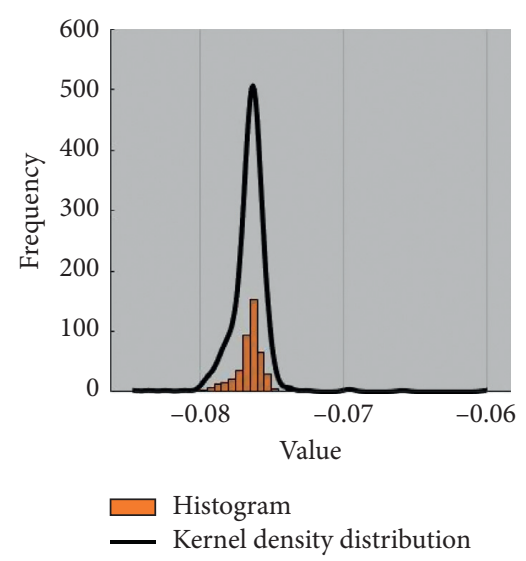

(d)

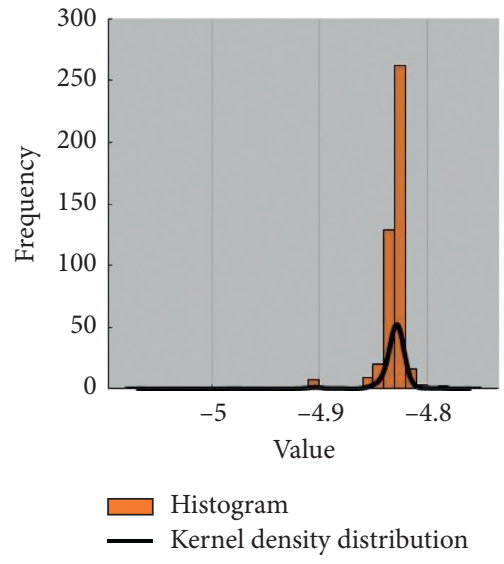

(b)

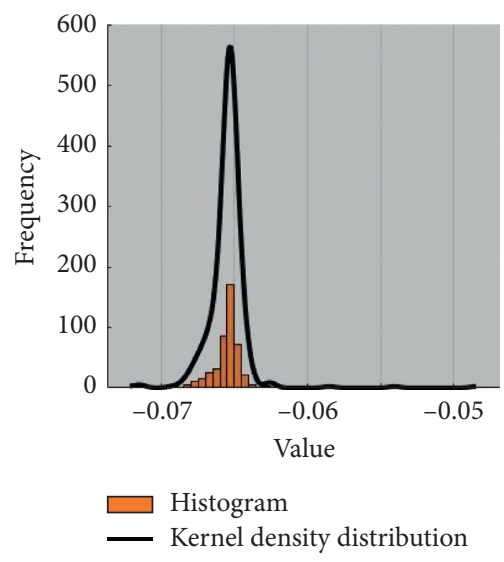

(e)

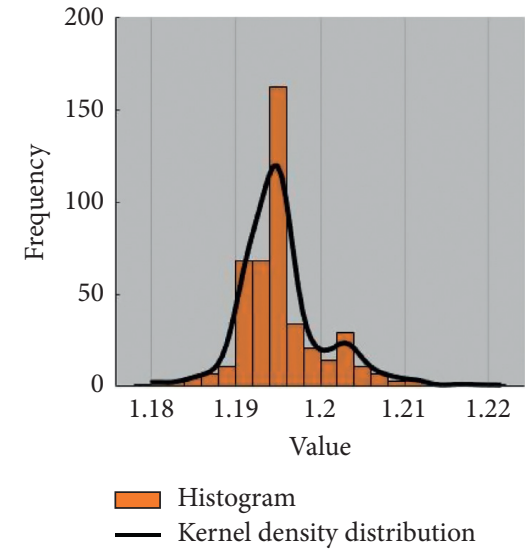

(c)

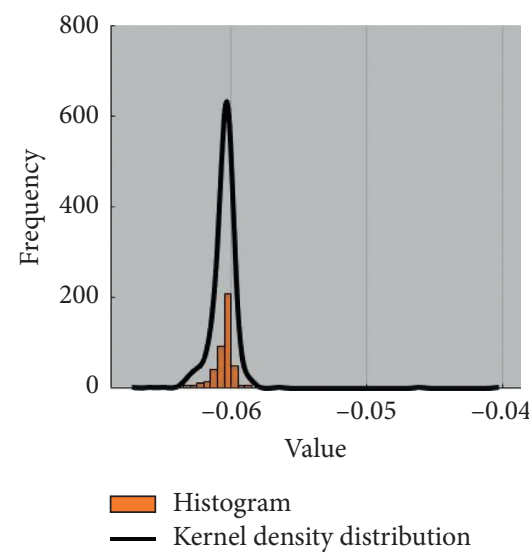

(f)

FIgURE 4: Empirical distributions of all the parameters: (a) $\lambda_{e_{i}}$; (b) $\lambda_{l_{i}}$; (c) $\lambda_{a}$; (d) $\lambda_{c_{5}}$; (e) $\lambda_{c_{4}}$; (f) $\lambda_{c_{3}}$.

peak and very long right-hand tails; (2) a lognormal distribution requires the random parameter to be positive, but the parameters for effective crowding were negative, so we needed to convert them to positive values in distributions; and (3) if we convert the parameters to their negative numbers, then the distributions will not be lognormal distributions anymore because the distributions will change from right-skewed to left-skewed.

In mixed logit models, for variables following either normal distributions $X \sim N\left(\mu, \sigma^{2}\right)$ or transformed lognormal distributions $\ln (X+\delta) \sim N\left(\mu, \sigma^{2}\right)$, the mean $\mu$ and standard deviation $\sigma$ were to be estimated. The value of $\delta$ representing the number of units that a lognormal distribution has been moved over to the left was enumerated from 0.1 to 3 with the step size 0.1 . For each enumeration, the mixed logit model was estimated with maximum simulated likelihood method with 100 modified Latin hypercube sampling (MLHS) draws [61]. The starting values of standard deviation were 0.01 , while the starting values of means for normal distribution were the corresponding estimates of logit model, and the ones for lognormal distributions were calculated based on the estimates of logit model, the standard deviation, and the number of units to be moved. Table 12 shows the optimal estimation result.

All the parameters passed significance tests, which shows taste variation did exist among commuters and the 
TABLE 12: The estimates of mixed logit departure time choice model.

\begin{tabular}{|c|c|c|c|c|c|c|c|c|c|}
\hline \multirow{2}{*}{ Parameter } & \multirow{2}{*}{ Distribution } & \multirow{2}{*}{$\delta$ value } & \multicolumn{2}{|c|}{$\mu$} & \multicolumn{2}{|c|}{$\sigma$} & \multirow{2}{*}{ Mean } & \multirow{2}{*}{ Std. } & \multirow{2}{*}{ Share $<0$} \\
\hline & & & Value & $T$-stat & Value & $T$-stat & & & \\
\hline$\lambda_{e}$ & Normal & - & -7.690 & -8.836 & 16.905 & 11.852 & -7.671 & 16.900 & $67.53 \%$ \\
\hline$\lambda_{l}$ & Normal & - & -42.655 & -10.112 & -19.157 & -10.096 & -42.662 & 19.138 & $98.74 \%$ \\
\hline$\lambda_{c_{5}}$ & Lognormal & 2.4 & 0.616 & 12.180 & 0.049 & 4.861 & -0.546 & 0.091 & $99.99 \%$ \\
\hline$\lambda_{c_{4}}^{c_{5}}$ & Lognormal & 2.4 & 0.752 & 19.842 & 0.062 & 6.856 & -0.275 & 0.131 & $97.73 \%$ \\
\hline$\lambda_{c_{3}}^{c_{4}}$ & Lognormal & 2.4 & 0.791 & 25.756 & -0.157 & -6.996 & -0.167 & 0.354 & $70.47 \%$ \\
\hline$\lambda_{a}^{3}$ & Normal & - & 11.025 & 12.286 & 6.819 & 11.139 & 11.033 & 6.824 & $5.27 \%$ \\
\hline Log-likelihood & & -1105.812 & & & & & & & \\
\hline Adjusted $\rho^{2}$ & & 0.679 & & & & & & & \\
\hline
\end{tabular}

Note. All parameters are significant at the $1 \%$ level. $\lambda_{e}$ : the reluctance to change original departure time to early side; $\lambda_{l}$ : the reluctance to change original departure time to late side; $\lambda_{c_{k}}(k=1-5)$ : the unit impact of crowding cost of Grade $k$ crowding; $\lambda_{a}$ : the unit impact of arrival time value.

assumptions of distributions we made were reasonable. When the estimation result reached its optimum, the transformed lognormal distributions were moved over 2.4 units to the left. Its adjusted $\rho^{2}$ was 0.27 higher than the one of logit model, which indicates the mixed logit model better fits the data.

The mean values of parameters representing the reluctances of commuters to switch their departure time to either early or late side were negative, with much higher absolute values for late side, showing that commuters were more unwilling to move their departure time forward. The distribution of $\lambda_{e}$ had $32.47 \%$ on the positive side, while the one of $\lambda_{l}$ had only $1.26 \%$. This finding suggests there was still a part of commuters who accept departing earlier or later. It can be explained by the fact that although commuters' original departure times are within the acceptable range, they are not exactly their preferred arrival times. Switching departure time earlier or later may allow them closer to their preferred arrival times. But it is worth noting that the percentage of $\lambda_{l}$ being on the positive side was very low. Combining with the asymmetrical responses of commuters in arrival time valuation, we could conclude that the whole commuter group averts to departing later through setting both a higher threshold for them to switch and a greater disutility for each unit of late arrival, which reemphasises that commuters react differently to earlier and later departure times and try to avoid being later at work/school, which has been found by other researchers [62, 63].

Regarding crowding impact, all the weights of effective crowding costs had negative mean values, with the absolute values increasing as crowding situation upgrades. It shows that the higher the grade of crowding is, the bigger the impact each unit of crowding cost has on commuters' departure time choice. The difference between the mean weights of crowding costs of Grades 5 and 4 was 0.27, 0.16 higher than the one between Grades 4 and 3. Emphasis should be put on that the difference between Grade 3 and Grade 2 was 0.17 , a bit greater than the one between 4 and 3. This is mainly because that Grade 2 crowding does not have an impact on departure time choice, which is a qualitative change. On the other hand, the standard deviations of the parameter distributions decreased with the upgrade of crowding level. The weight of Grade 3 crowding cost had the greatest standard deviation of 0.35 , while the ones for Grade 4 (0.13) and Grade 5 (0.09) were much less.
It implies that commuters had more dispersed tastes in a less crowded situation, while less difference existed in their tastes when they were facing higher grades of crowding. One of the reasons that could explain this finding is that there is no physical contact in Grade 3 crowding, and the weights that commuters give to the impact of Grade 3 crowding mainly depend on their perceptions of personal bubbles. If a commuter is more sensitive about the distance between him/her and other passengers, he/she is more likely to attach a higher weight to Grade 3 crowding cost. As for Grade 4 and Grade 5 crowding, commuters' perceptions were more concentrated.

The only parameter with a positive mean value was $\lambda_{a}$, the one for arrival time value, which is consistent with our analysis. Only $5.27 \%$ of the distribution was on the negative side. For most of the commuters, arrival time value had an increasing effect on the utility of the departure time choice. The ratio between the mean values of parameters of arrival time value and crowding costs shows that for every 0.1 unit decrease in arrival time value, commuters needed to experience a reduction of 2.02, 4.02, or 6.61 units in crowding costs of Grades 5, 4, and 3 , that is, $2.02,4.73$, or $11.01 \mathrm{~min}$ in the corresponding crowding situation. Note that here a reduction means the crowding situation changes from its original status to the one less crowded than or equal to Grade 2 crowding. If the crowding situation only degrades by one grade, then a reduction of 4.07 units in the crowding cost (3.54 $\mathrm{min})$ for Grades 5 to $4,10.25$ units $(8.28 \mathrm{~min})$ for Grades 4 to 3, and 6.61 units ( $11.01 \mathrm{~min}$ ) for Grades 3 to 2 was needed to offset the 0.1 unit decrease in the arrival time value. Averagely speaking, a commuter would be motivated to depart earlier with at least 14.06, 27.93, or 45.94 units of reduction in the crowding costs of Grades 5,4 and 3, while the reduction needed to motivate a commuter to depart later is 5.56 times of the one for departing earlier. These results could explain why the passengers who experienced higher grade of crowding were more likely to switch their departure time. It also proves that arriving at preferred time is still one of the most important influencing factors of commuters' departure time choice.

Traditionally, both transport authorities and railway operators try to alleviate crowding with little consideration of commuters' departure time choice. The model in this 
paper could be used to predict commuters' departure time under different crowding circumstances due to different time periods, route choices, and policies and be used to compare different scenarios and validate or evaluate some crowding alleviation strategies. Because crowding situation is a dynamic status, so for relieving crowding, two major contexts should be considered. The first one is adjusting commuters' departure time choice without changing their route choices. The results of both the arrival time valuation and departure time choice models give some implications to where and who should be focused on and what potential actions could be. Because from Grades 3 to 5, crowding has an increasing impact on departure time choice while commuters' perceptions of crowding cost get more concentrated, so the priority of crowding alleviation should be firstly given to the sections where Grade 5 crowding situation happens as both the population of commuters per vehicle and the proportion of being influenced are much greater and the commuters are more willing to switch their departure times with a greater extent of change. For those commuters who experience Grade 5 crowding, the reasons that prevent them from switching departure time are the reluctances to switch departure time to both sides and the reduction of arrival time value. To overcome these barriers, actions could be taken to adjust the working time schemes of this group of commuters. In our case, why commuters are much more reluctant to switch their times to late side can be explained by the fact that most of the companies in Shanghai implement fixed working time scheme, which does not allow lateness or allow little lateness. On the other hand, commuters try to arrive at their preferred arrival times, which are usually before their work start times. Flexible or later work start time may help to encourage commuters to adjust their preferred arrival times and, therefore, switch their departure times. This could move a part of commuters who experience Grade 5 crowding to a less crowded situation in a different time period and mitigate the crowding situation of peak time, leading to a more evenly distributed travel demand. Based on commuters' destinations, place-based gradient work start time could also be considered to regulate the peak time crowding. Once Grade 5 crowding situation is eased, the attention could be moved on to less crowded situation. But one thing to note is that because the reluctances to switch departure time to both sides contribute more to the utility of departure time as the total crowding cost decreases, so the effectiveness of cost and effort will drop with the degrading of crowding. The second context is guiding commuters to other less crowded routes. Changing route will influence not only commuters' journey time, experienced crowding situation, but also their departure times, so the guidance should provide commuters with suggestions about not only route but also departure time choice. The combinations of both should be compared by using the departure time choice model and route choice model together to guarantee the new choices are tempting enough to shift commuters from their original choices. It is worth emphasising that any one of actions may change the network to a new crowding status; thus, commuters may reselect their departure times, which could be predicted by the departure time choice model. It can help policymakers to better understand the interaction between commuters' departure time choice and other influencing factors of crowding.

\section{Conclusions}

This study aims at identifying how crowding impacts the departure time choice of commuters in urban rail transit and its trade-off with arrival time value. A submodel of arrival time valuation introduced the reference point approach from prospect theory to capture the asymmetrical responses of commuters to arrivals on early and late sides. On this basis, a mixed logit-based departure time choice model was constructed with the degrees of crowding being measured by a five-grade standard according to commuters' perceptions. We used multinomial logit models to compare two hypotheses of effective crowding specifications. Whether the mixing is needed was then tested statistically and the assumptions of parameter distributions were picked based on their empirical results. Both models were estimated with the survey data of commuters in Shanghai Metro. The main findings of this study are summarised as follows:

(i) Commuters in urban rail transit took preferred arrival time as the only reference point, instead of work/school start time in most of the existing studies. This leads to the result that commuters felt perceived loss and exhibited risk-seeking even though their arrival time value may be positive. Furthermore, commuters responded asymmetrically to arrivals on early and late sides with attaching more disutility to being late.

(ii) Commuters did have taste variation on the influencing factors of departure time choice. The distributions of the reluctances to switch departure time to early or later side and the parameter of arrival time value could be assumed to be normally distributed, while the ones of the weights of crowding cost followed transformed lognormal distributions.

(iii) Crowding did have impact on the departure time choice of commuters; however, not all degrees of crowding had an impact. Only the crowding ranging from Grades 3 to 5 influenced the departure time choice of commuters significantly. Meanwhile, the reluctances to switch departure time to early and late sides and arrival time value also played roles in the decision making of departure time.

(iv) Each unit of crowding cost had a bigger impact on commuters' departure time choice with an upgrade of crowding situation, while commuters' tastes on the weights of crowding cost got more dispersed in a less crowded situation.

This departure time choice model can be directly used to predict the departure time choice and update of commuters. We aim at integrating it into a potential dynamic transit assignment model by combining with route choice and update model to predict the passenger pattern in the future 
when a brand-new or modified urban rail network is proposed. It can also be used to analyse policy regarding reducing peak time crowding and develop operational strategies.

\section{Data Availability}

The research data used to support the findings of this study are available from the corresponding author upon request.

\section{Conflicts of Interest}

The authors declare that there are no conflicts of interest regarding the publication of this paper.

\section{References}

[1] H. Kato, Y. Kaneko, and M. Inoue, "Comparative analysis of transit assignment: evidence from urban railway system in the Tokyo Metropolitan Area," Transportation, vol. 37, no. 5, pp. 775-799, 2010.

[2] K. M. Kim, S.-P. Hong, S.-J. Ko, and D. Kim, "Does crowding affect the path choice of metro passengers?" Transportation Research Part A: Policy and Practice, vol. 77, pp. 292-304, 2015.

[3] F. Leurent and K. Liu, "On seat congestion, passenger comfort and route choice in urban transit: a network equilibrium assignment model with application to paris," TRB. Annual Meeting of the Transportation Research Board Session Transit Capacity and Quality of Service, vol. 434, pp. 1996-2006, 2009.

[4] A. J. Pel, N. H. Bel, and M. Pieters, "Including passengers' response to crowding in the Dutch national train passenger assignment model," Transportation Research Part A: Policy and Practice, vol. 66, no. 1, pp. 111-126, 2014.

[5] S. Raveau, J. C. Muñoz, and L. de Grange, "A topological route choice model for metro," Transportation Research Part A: Policy and Practice, vol. 45, no. 2, pp. 138-147, 2011.

[6] S. Raveau, Z. Guo, J. C. Muñoz, and N. H. M. Wilson, "A behavioural comparison of route choice on metro networks: time, transfers, crowding, topology and socio-demographics," Transportation Research Part A: Policy and Practice, vol. 66, no. 1, pp. 185-195, 2014.

[7] T. Cox, J. Houdmont, and A. Griffiths, "Rail passenger crowding, stress, health and safety in Britain," Transportation Research Part A: Policy and Practice, vol. 40, no. 3, pp. 244258, 2006.

[8] M. Wardman and G. Whelan, "Twenty years of rail crowding valuation studies: evidence and lessons from British experience," Transport Reviews, vol. 31, no. 3, pp. 379-398, 2011.

[9] Y.-H. Cheng, "Exploring passenger anxiety associated with train travel," Transportation, vol. 37, no. 6, pp. 875-896, 2010.

[10] F. Maunsell, "Demand management techniques-peak spreading," Report for Department for Transport, Transport for London and Network Rail, London, UK, 2007.

[11] D. Ettema and H. Timmermans, "Modeling departure time choice in the context of activity scheduling behavior," Transportation Research Record: Journal of the Transportation Research Board, vol. 1831, no. 1, pp. 39-46, 2007.

[12] C. Hendrickson and E. Plank, "The flexibility of departure times for work trips," Transportation Research Part A: General, vol. 18, no. 1, pp. 25-36, 1984.

[13] R.-C. Jou, R. Kitamura, M.-C. Weng, and C.-C. Chen, "Dynamic commuter departure time choice under uncertainty,"
Transportation Research Part A: Policy and Practice, vol. 42, no. 5, pp. 774-783, 2008.

[14] I. Kristoffersson, "Implementation of model for departure time choice," in Proceedings of the TRISTAN VI, pp. 1-19, Phuket Island, Thailand, June 2007.

[15] R. Noland and K. Small, Travel-Time Uncertainty, Departure Time Choice, and the Cost of Morning Commutes, Transportation Research Board, no. 1493, pp. 150-158, Washington, DC, USA, 1995.

[16] K. A. Small, "The scheduling of consumer activities: work trips," The American Economic Review, vol. 72, no. 3, pp. 467-479, 1982.

[17] B. W. Y. Siu and H. K. Lo, "Punctuality-based route and departure time choice," Transportmetrica A: Transport Science, vol. 10, no. 7, pp. 585-621, 2014.

[18] R. Arnott, A. de Palma, and R. Lindsey, "Departure time and route choice for the morning commute," Transportation Research Part B: Methodological, vol. 24, no. 3, pp. 209-228, 1990.

[19] A. de Palma, M. Ben-Akiva, C. Lefevre, and N. Litinas, "Stochastic equilibrium model of peak period traffic congestion," Transportation Science, vol. 17, no. 4, pp. 430-453, 1983.

[20] L. Han, S. Ukkusuri, and K. Doan, "Complementarity formulations for the cell transmission model based dynamic user equilibrium with departure time choice, elastic demand and user heterogeneity," Transportation Research Part B: Methodological, vol. 45, no. 10, pp. 1749-1767, 2011.

[21] H.-J. Huang and W. H. K. Lam, "Modeling and solving the dynamic user equilibrium route and departure time choice problem in network with queues," Transportation Research Part B: Methodological, vol. 36, no. 3, pp. 253-273, 2002.

[22] H. S. Mahmassani and G.-L. Chang, "Experiments with departure time choice dynamics of urban commuters," Transportation Research Part B: Methodological, vol. 20, no. 4, pp. 297-320, 1986.

[23] B. Ran, R. W. Hall, and D. E. Boyce, "A link-based variational inequality model for dynamic departure time/route choice," Transportation Research Part B: Methodological, vol. 30, no. 1, pp. 31-46, 1996.

[24] H. Yang and Q. Meng, "Departure time, route choice and congestion toll in a queuing network with elastic demand," Transportation Research Part B: Methodological, vol. 32, no. 4, pp. 247-260, 1998.

[25] A. de Palma, M. Kilani, and S. Proost, "Discomfort in mass transit and its implication for scheduling and pricing," Transportation Research Part B: Methodological, vol. 71, pp. 1-18, 2015.

[26] A. de Palma, R. Lindsey, and G. Monchambert, "The economics of crowding in rail transit," Journal of Urban Economics, vol. 101, pp. 106-122, 2017.

[27] C. Harada, S. Iwakura, and S. Morichi, "Analysis and modeling of commuters' departure time in urban railway network," Proceedings of Infrastructure Planning, vol. 26, pp. 4-1, 2002, in Japanese.

[28] S. Iwakura and C. Harada, "A model system of departure time choice for commuter trips by metropolitan railway," Transport Policy Studies' Review, vol. 8, no. 3, pp. 4-15, 2005, in Japanese.

[29] Q. Tian and H. Huang, "An equilibrium ride model for subway passengers with arrival early penalty," Communication and Transportation Systems Engineering and Information, vol. 4, 2004. 
[30] Q. Tian, H.-J. Huang, and H. Yang, "Equilibrium properties of the morning peak-period commuting in a many-to-one mass transit system," Transportation Research Part B: Methodological, vol. 41, no. 6, pp. 616-631, 2007.

[31] W. Wu and H. Huang, "Model of subway commuters' departure time choice with in-carriage congestion and arrival early/late penalty," Journal of Transportation Systems Engineering and Information Technology, vol. 9, no. 1, pp. 128-132, 2009.

[32] W. S. Vickrey, "Congestion theory and transport investment," The American Economic Review, vol. 59, no. 2, pp. 251-260, 1969.

[33] H. Ieda, K. Tsuchiya, L. B. Phan, and T. Okamura, "Development of the commuter demand concentration model based on a time-space network scheme," Doboku Gakkai Ronbunshu, vol. 2002, no. 702, pp. 65-79, 2002.

[34] S. Iwakura, C. Harada, and S. Suzuki, "Comparative analysis of choice set for commuting time of day choice model in urban railway networks," Infrastructure Planning Review, vol. 20, pp. 485-492, 2003.

[35] H. Yang and Y. Tang, "Managing rail transit peak-hour congestion with a fare-reward scheme," Transportation Research Part B: Methodological, vol. 110, pp. 122-136, 2018.

[36] S. Peer, J. Knockaert, and E. T. Verhoef, "Train commuters' scheduling preferences: evidence from a large-scale peak avoidance experiment," Transportation Research Part B: Methodological, vol. 83, pp. 314-333, 2016.

[37] Y. Soyama, Y. Kaneko, and H. Kato, "Departure time choice under the condition of daily service delay in urban railway," Proceedings of Infrastructure Planning, vol. 41, pp. 1-4, 2010, in Japanese.

[38] D. A. Hensher, J. M. Rose, and A. T. Collins, "Identifying commuter preferences for existing modes and a proposed Metro in Sydney, Australia with special reference to crowding," Public Transport, vol. 3, no. 2, pp. 109-147, 2011.

[39] L. Haywood and M. Koning, "Estimating Crowding Costs in Public Transport," Deutsches Institut für Wirstchaftsforschung, Berlin, Germany, 2013.

[40] R. Prud'homme, M. Koning, L. Lenormand, and A. Fehr, "Public transport congestion costs: the case of the Paris subway," Transport Policy, vol. 21, pp. 101-109, 2012.

[41] N. Douglas and G. Karpouzis, "Estimating the passenger cost of train overcrowding," in Proceedings of the 29th Australian Transport Research Forum, Australia, 2006.

[42] W. H. K. Lam, C.-Y. Cheung, and C. F. Lam, "A study of crowding effects at the Hong Kong light rail transit stations," Transportation Research Part A: Policy and Practice, vol. 33, no. 5, pp. 401-415, 1999.

[43] M. Wardman, "Valuing convenience in public transport," University of Leeds, UK, Discussion Paper No. 2014-02, 2014.

[44] M. Batarce, J. C. Muñoz, J. de Dios Ortúzar, S. Raveau, C. Mojica, and R. A. Ríos, "Use of mixed stated and revealed preference data for crowding valuation on public transport in Santiago, Chile," Transportation Research Record: Journal of the Transportation Research Board, vol. 2535, no. 1, pp. 73-78, 2015.

[45] UK Department For Transport, "Rail passenger numbers and crowding statistics, notes and definitions," p. 12, Department for Transport, London, UK, 2013.

[46] L. Hirsch and K. Thompson, "I can sit but I'd rather stand: commuter's experience of crowdedness and fellow passenger behaviour in carriages on Australian metropolitan trains," Proceedings in Proeedings of the Australasian Transport
Research Forum (ATRF), vol. 34, Adelaide, South Australia, September 2011.

[47] Kittelson \& Associates, Inc., T. R. Board, National Academies of Sciences and Medicine et al., Transit Capacity and Quality of Service Manual, The National Academies Press, Washington, DC, USA, 3rd edition, 2013.

[48] E. Kroes, M. Kouwenhoven, L. Debrincat, and N. Pauget, "The value of crowding for public transport in the paris region," in Proeedings of the European Transport Conference 2013, OECD Publishing, Frankfurt, Germany, September 2013.

[49] Z. Li and D. Hensher, "Crowding in public transport: a review of objective and subjective measures," Journal of Public Transportation, vol. 16, no. 2, pp. 107-134, 2013.

[50] G. A. Whelan and J. Crockett, "An investigation of the willingness to pay to reduce rail overcrowding," in Proceedings of the International Conference on Choice Modeling, vol. 16, Harrogate, UK, April 2009.

[51] A. Tirachini, L. Sun, A. Erath, and A. Chakirov, "Valuation of sitting and standing in metro trains using revealed preferences," Transport Policy, vol. 47, pp. 94-104, 2016.

[52] D. Kahneman and A. Tversky, "Prospect theory: an analysis of decision under risk," Econometrica, vol. 47, no. 2, pp. 263-291, 1979.

[53] H. A. Simon, "A behavioral model of rational choice," The Quarterly Journal of Economics, vol. 69, no. 1, pp. 99-118, 1955.

[54] Y. Cheng, X. Ye, and Z. Wang, "Arrival time valuation of commuters in urban rail transit," Transport, vol. 34, no. 3, pp. 383-393, 2019.

[55] R.-C. Jou and R. Kitamura, "Commuter departure time choice: a reference-point approach," in Proceedings of the 13th Mini-EURO Conference-Handling Uncertainty in the Analysis of Traffic and Transportation Systems, vol. 16, pp. 149-155, Bari, Italy, June 2002.

[56] T. Sumi, Y. Matsumoto, and Y. Miyaki, "Departure time and route choice of commuters on mass transit systems," Transportation Research Part B: Methodological, vol. 24, no. 4, pp. 247-262, 1990.

[57] D. McFadden and K. Train, "Mixed MNL models for discrete response," Journal of Applied Econometrics, vol. 15, no. 5, pp. $447-470,2000$.

[58] D. A. Hensher and W. H. Greene, "The mixed logit model: the state of practice," Transportation, vol. 30, no. 2, pp. 133-176, 2003.

[59] M. Kosaka, "Analysis of commuters' intention to change departure time in Tokyo metropolitan area," Master thesis, Shibaura Institute of Technology, Tokyo, Japan, 1999.

[60] K. E. Train, Discrete Choice Methods with Simulation, Cambridge University Press, Cambridge, UK, 2009.

[61] S. Hess, K. E. Train, and J. W. Polak, "On the use of a modified Latin hypercube sampling (MLHS) method in the estimation of a mixed logit model for vehicle choice," Transportation Research Part B: Methodological, vol. 40, no. 2, pp. 147-163, 2006.

[62] M. Thorhauge, E. Cherchi, and J. Rich, "How flexible is flexible? accounting for the effect of rescheduling possibilities in choice of departure time for work trips," Transportation Research Part A: Policy and Practice, vol. 86, pp. 177-193, 2016.

[63] H. Li, X. Li, X. Xu, J. Liu, and B. Ran, "Modeling departure time choice of metro passengers with a smart corrected mixed logit model-a case study in Beijing," Transport Policy, vol. 69, pp. 106-121, 2018. 